\title{
Social support and high resilient coping in carers of people with dementia
}

\author{
Abstract \\ High resilience is associated improved carer outcomes. Both individual factors and the \\ availability of social support have been linked with resilience. This study was conducted to \\ compare socio-demographic characteristics and the availability of social support for carers \\ with low and high resilient coping, and identify if any domain of social support predicted high \\ resilient coping in informal carers of people with dementia. The participants in this cross \\ sectional survey included 108 informal carers of people with dementia. Findings showed the \\ availability of emotional/informational support was most likely to predict resilient coping and \\ tangible support the least likely. However, when controlling for all covariates, only gender \\ predicted high resilient coping, individual social support domains were no longer significant. \\ Therefore, as no single domain of social support has a significantly greater influence on \\ resilient coping, therefore service providers should enable carers to build a wide, multi- \\ function support network.
}

\section{Keywords}

Carer; dementia; resilient coping; social support. 


\section{What is already known about the topic?}

- Carers of people with dementia are a greater risk of social isolation.

- High resilient coping is associated with greater wellbeing.

- Support from friends, family and the wider community can aid carer resilience.

\section{Highlights}

- This study shows that only a small proportion of carers report they always have access to social support from friends or family.

- Social support is multi-dimensional and no single domain of social support has greater influence on resilience.

- Female carers were more likely to report high resilient coping. 


\section{Background}

Informal carers are often the main providers of support to people with dementia living in the community ${ }^{1}$. It can be difficult for an individual to balance their own needs with those of the person they care for, with some carers becoming socially isolated, experiencing ill health and financial strain ${ }^{2,3}$. However, not all carers experience these negative consequences. Resilience describes positive adaptation to stressful situations ${ }^{4}$ and encompasses both individual characteristics and extrinsic factors, including social support from their family and the wider community ${ }^{5}$.

There are inconsistencies within the literature regarding the impact individual sociodemographic characteristics have on carer outcomes. The role gender plays in resilience is unclear, differences between males and females have been observed in specific groups (e.g. adolescents ${ }^{6}$ ) but overall there is a lack of evidence examining gender and resilience and a need to examine this in other populations ${ }^{7}$. Living with the care recipient has been associated with lower resilience ${ }^{8}$ and adult child carers who live with a parent with dementia are more likely to have a smaller social network than spousal carers ${ }^{9}$. Other findings on the relevance of spousal relationship are contradictory. Marriage to the person with dementia has been associated with associated with both, increased burden and psychological distress ${ }^{10}$ and improved mental health and lower burden ${ }^{11}$.

High resilience and specifically resilient coping, are related to improved carer outcomes and are associated with greater availability of social support ${ }^{12}$ and lower levels of burden, stress, and depression ${ }^{13}$. Carers with high resilient coping are more likely to be goal-directed, have a belief that they can overcome challenges and have greater subjective well-being ${ }^{14,15}$. Different dimensions of social support have been shown to bring specific benefits. For example emotional/informational support and positive social interaction are associated with cognitive function in older adults ${ }^{16}$. These two dimensions are also associated with perceived general health in parent carers of children with autism spectrum disorder ${ }^{12}$. A recent qualitative study found that, where available, emotional/informational and tangible 
support facilitated resilience for carers who were providing end of life care ${ }^{17}$. Identifying which dimensions of social support influence resilience in the context of dementia caring may help healthcare practitioners and service providers tailor support services for these carers. Based on current literature, we hypothesised that carers who report high resilient coping would have greater perceived social support. As a secondary hypothesis, we anticipated that high resilient coping would be associated with emotional/informational support and tangible support in line with qualitative studies ${ }^{18}$. We also wanted to explore the role of other dimensions of social support in resilient coping.

\section{Methods}

Study design and recruitment

Between July 2016 and August 2017 a cross-sectional postal survey of informal carers currently providing care for a close friend or family member with dementia living in the UK was carried out. Carers were invited to take part in the study via an online forum hosted by the Alzheimer's Society UK and through leaflets distributed at dementia cafes and carer events in Norfolk, UK. Carers who expressed an interest in the study were sent an information sheet via post or email. A consent form, questionnaire pack and pre-paid return envelope were then posted to those who agreed to take part.

Instruments

Socio-demographic variables

Socio-demographic data were collected about the carer, including gender, age group, education level, employment status, relationship to the person with dementia and whether the carer lived with the person with dementia. 
Resilience

The Brief Resilient Coping Scale (BRCS) ${ }^{14}$, was used to determine carers level of resilient coping. The measure is comprised of four questions answered on a five-point Likert scale. Questions assess the individual's ability to cope with stress in an adaptive manner through creative problem solving, controlling reactions to stressful events, growing in positive ways through dealing with difficulties and actively seeking ways to replace losses which occur in life. Respondent's rate their answers from 'does not describe me at all' (1) through to 'describes me very well' (5). Scores can range from 4-20, higher scores indicate greater resilient coping ${ }^{14}$.

\section{Social support}

The Medical Outcomes Study - social support survey (MOS-SSS) ${ }^{19}$, a multi-dimensional self-report scale was used to analyse the carers perceived availability of social support. The survey has four sub-scales, measuring emotional/informational support; tangible support; affection and positive social interaction. Responses to the scale are measured on a 5-point Likert scale and range from never (0) to always (4). Higher scores indicate the greater availability of social support. To obtain a score for each subscale, we calculated the average of the scores for each item in the subscale as per the author's instructions ${ }^{20}$.

\section{Level of dependence of the person with dementia}

The Bristol Activities of Daily Living (BADLS) ${ }^{21}$ was used to assess how dependent the person with dementia was on their carer. It is a valid and reliable scale which measures the assistance required by the care recipient for both basic and instrumental activities of daily living $^{22}$. It asks carers to rate the average level of dependence of the person over the last 
two weeks in specific activities such as eating, dressing and bathing. Scores range from 060 , scores ranging from 0-20 indicate low dependency, 21-40 medium dependency and scores between 41 and 60 indicate high dependency.

\section{Data analyses}

Descriptive statistics were used to report socio-demographic characteristics. Variables included carer age, gender, education, employment, residence (with or without the person with dementia), and relationship to the person with dementia. Demographic differences between carers with high and low resilient coping were estimated using Chi-square tests. Kolmogorov-Smirnoff tests and visual inspection of histograms were used to assess the normality of the resilience measure (BRCS) and subscales of the social support measure (MOS-SSS). Resilient coping was normally distributed. In order to compare groups, a dichotomised value for resilience was established using the mean score of the sample (BRCS total), values equal to or below the mean score $(\leq 13)$ were categorised into the low resilient coping group, and carers greater than the mean $(\geq 14)$, included in the high resilient coping group.

Means and standard deviations were calculated for each domain of social support for the group as a whole and for both the low and high resilient coping groups. Social support data were not normally distributed for any of the subscales. Therefore, the Mann-Whitney $U$ test of significance was used for testing the hypothesis that carers with low and high resilient coping differed in their levels of perceived support. Effect sizes were calculated from the $z$ scores of the Mann-Whitney $U$ tests $^{23}$. Collinearity diagnostics showed all variance inflation factors (VIF) were $<3$ and tolerance was above 0.3 .

Predictors of resilient coping were investigated using logistic regression modeling. First, considering resilient coping as the dependent variable (high vs low resilient coping), each predictive variable was entered on its own, i.e. each domain of social support and the socio- 
demographic variables (model A). Next, a multivariable logistic regression model (model B) was used, taking resilient coping as the dependent variable (high vs low resilient coping) and all predictor variables entered together to control for any confounding effects. All data analyses were computed in IBM SPSS Statistics v.25 and significance was set at $p \leq 0.05$.

\section{Ethical approval}

The Research Ethics Committee of the Faculty of Medicine and Health Sciences at the (Removed for peer review) gave ethical approval for this study.

\section{Results}

\section{Sample Characteristics}

Of the 150 carers who expressed an interest in the study, 108 returned questionnaires (72\%). Two additional questionnaires were returned but not included in the study as the participant was no longer caring for the person with dementia and so did not meet the inclusion criteria. The majority of the sample were women (69\%). $61 \%$ of carers were aged 70 years or above. Spousal relationship was most common (61\%), as was carer coresidence with the person with dementia $(78 \%)$. The characteristics of respondents were comparable to those of dementia carers in the UK as a whole ${ }^{24}$. 


\section{Low resilient High resilient Chi Square tests \\ coping $(n=53) \quad$ coping $(n=55)$}

\section{Gender}

$\begin{array}{lll}\text { Male } & 23(43 \%) & 10(18 \%)\end{array}$

Female $\quad 30(57 \%) \quad 45(82 \%)$

Age group (years)

$\begin{array}{lll}<70 & 19(36 \%) & 23(42 \%) \\ 70-79 & 19(36 \%) & 21(38 \%) \\ 80+ & 15(28 \%) & 11(20 \%)\end{array}$

Formal education (years)

Employment

$\begin{array}{lll}\text { Up to } 12 & 23(43 \%) & 22(40 \%) \\ \text { Up to } 14 & 15(28 \%) & 17(31 \%) \\ \text { Up to } 17+ & 15(28 \%) & 16(29 \%)\end{array}$

$\begin{array}{lll}\text { FT/PT } & 9(17 \%) & 12(22 \%) \\ \text { Retired / Not } & 44(83 \%) & 43(78 \%)\end{array}$

working

Spousal carers

$\begin{array}{lll}\text { Spouse } & 35(66 \%) & 31(56 \%) \\ \text { Other } & 18(34 \%) & 24(44 \%)\end{array}$

Carer resides with the PWD

$\begin{array}{lll}\text { Yes } & 45(85 \%) & 39(71 \%) \\ \text { No } & 8(15 \%) & 16(29 \%)\end{array}$

PWD level of dependence $\chi^{2}(1, \mathrm{n}=108)=8.09, p=0.004^{*}$

$$
\chi^{2}(2, \mathrm{n}=108)=1.06, p=0.59
$$

$\chi^{2}(2, n=108)=0.14, p=0.93$

$\chi_{(1, n=108)}^{2}=0.40, p=0.53$

$\chi^{2}(1, n=108)=1.06, p=0.30$

$\chi^{2}(1, n=108)=3.06, p=0.08$

$\chi^{2}{ }_{(2, \mathrm{n}=105)}=0.44, p=0.80$

$\begin{array}{llr}\text { Low } & 14(26 \%) & 15(27 \%) \\ \text { Medium } & 26(49 \%) & 27(49 \%) \\ \text { High } & 13(25 \%) & 9(16 \%)\end{array}$

$\mathrm{PWD}=$ person with dementia, $\mathrm{FT}=$ full-time, $\mathrm{PT}=$ part time, ${ }^{*} p<0.05$.

Table 1: Socio-demographic characteristics of carers by high and low resilient coping.

As illustrated in Table 1, the sample of carers was split into two groups, low or high resilient coping based on BRCS scores. There were no significant differences between the groups for age $\left(\chi^{2}(2, \mathrm{n}=108)=1.06, p=0.59\right)$, education $\left(\chi^{2}{ }_{(2, \mathrm{n}=108)}=0.14, p=0.93\right)$, employment 
$\left(\chi_{(1, \mathrm{n}=108)}=0.40, p=0.53\right)$, relationship to the person with dementia $\left(\chi_{(1, \mathrm{n}=108)}^{2}=1.063, p=0.30\right)$ or residence with the person with dementia $\left(\chi_{(1, \mathrm{n}=108)}^{2}=3.06, p=0.08\right)$. Equally there was no difference between groups based on the level of dependency of the person with dementia $\left(\chi^{2}(2, \mathrm{n}=105)=0.44, p=0.80\right)$. However, there was a significant difference between groups for gender, with more women reporting high resilient coping $\left(\chi_{(1, \mathrm{n}=108)}^{2}=8.09, p=0.004\right)$.

Perceived availability of social support

When the sample was examined as a whole, only 4 (3.7\%) carers said they 'always' had access to all domains of social support. Tangible support was perceived as least available (Mean=1.74, SD=1.37), where $23(21.3 \%)$ participants scored zero for this domain, indicating they have no access to practical help from friends or family. Affectionate support was perceived as the most available (Mean $=2.45, \mathrm{SD}=1.34)$, where $30(27.8 \%)$ participants reported they always had access to this domain of social support.

Are there differences in social support between carers with high and low resilient coping?

When comparing carers with high and low resilient coping, those with low resilient coping consistently reported lower scores on all domains of social support, indicating they perceived they have less access to social support, as shown in Figure 1.

Low resilient carers reported significantly less availability of emotional/informational support than high resilient carers (Mean rank difference=20.17, $U=913.00, z=-3.35, p=0.001$ ). However, while the difference between carer groups was significant, the effect size of emotional/informational support on resilience was small $(\eta=0.10)$.

The perceived availability of tangible support was also significantly lower for carers who report low resilient coping (Mean rank difference 14.77, $U=1059.00, z=-2.47, p=0.014$ ) but 
the effect size of perceived availability of tangible support on resilient coping was again small $(\eta=0.06)$.

Likewise, there was also a significant difference between low and high resilient coping groups for affection (Mean rank difference 16.34, $U=1016.50 \mathrm{z}=-2.756, p=0.006$ ). There was a small effect size $(\eta=0.07)$ of affection on resilient coping.

Finally, low resilient coping carers also perceived they had less availability of positive social interaction than carers who had high resilient coping scores (Mean rank difference $=18.89$, $U=947.5, z=-3.175, p=0.001)$ and the effect size of positive social interaction on resilient coping was small $(\eta=0.09)$.

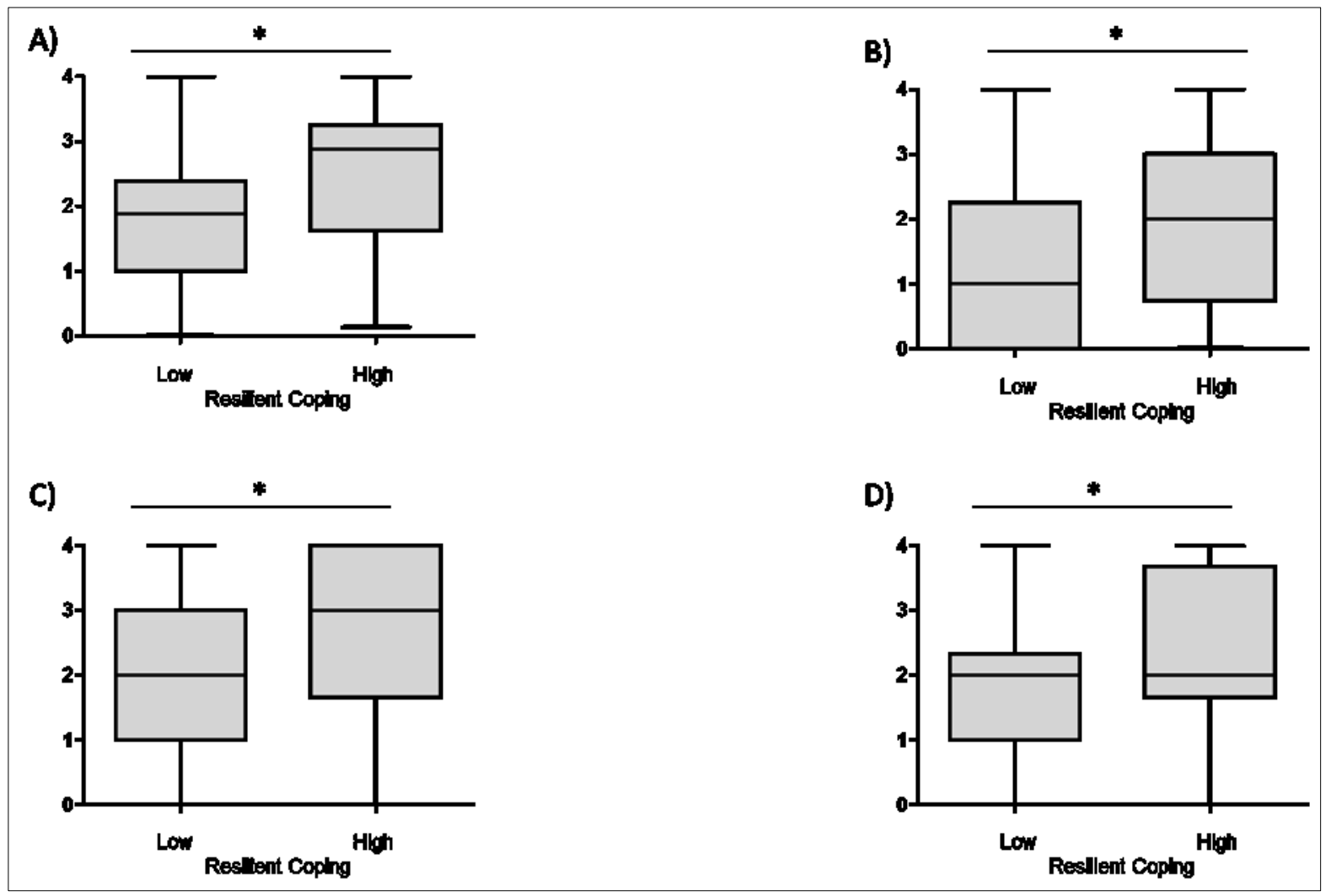

Figure 1. Comparisons of carers with low and high resilient coping for

A) emotional/informational support, B) tangible support, C) affection and D) social interaction. ${ }^{*} p<0.05$ 
Can social support predict resilient coping?

Each domain of social support significantly predicted high resilient coping, as shown in Model A, Table 2. Emotional/informational support had greatest influence on high resilient coping $(\mathrm{OR}=1.92,95 \% \mathrm{Cl}=1.29$ to $2.88, p=0.001)$. Carers with greater access to tangible support were also more likely to be highly resilient copers $(\mathrm{OR}=1.43,95 \% \mathrm{Cl}=1.07$ to 1.91 , $p=0.017)$. Equally, greater availability of affectionate support $(\mathrm{OR}=1.49,95 \% \mathrm{Cl} 1.10$ to 2.00 , $p=0.010)$ and positive social interaction $(\mathrm{OR}=1.76,95 \% \mathrm{Cl}=1.24$ to $2.49, p=0.002)$ predicted high resilient coping. Gender was a significant predictor, with females being more likely to be high resilient copers $(\mathrm{OR}=3.45,95 \% \mathrm{Cl}=0.44-8.27, \mathrm{p}=0.01)$.

Model B, table 2, reports the association between all social support and social demographic variables on resilience when adjusting for all other variables. While the model as a whole was significant $\left(\chi^{2}=29.82, p=0.013\right)$, no domain of social support individually predicted $h i g h$ resilient coping. 


\begin{tabular}{|c|c|c|}
\hline & MODEL A & MODEL B \\
\hline \multirow[t]{3}{*}{ Variables } & Each predictive variable on its & All predictive variables entered \\
\hline & own & simultaneously \\
\hline & OR $(95 \% \mathrm{Cl}), p$ value & OR $(95 \% \mathrm{Cl}), p$ value \\
\hline Emotional/informational support & $1.92(1.28-2.88), p=0.01^{*}$ & $1.71(0.85-3.42), p=0.13$ \\
\hline Tangible support & $1.43(1.07-1.91), p=0.01^{*}$ & $1.06(0.65-1.74), p=0.82$ \\
\hline Affection & $1.49(1.10-2.01), p=0.01^{*}$ & $0.98(0.55-1.74), p=0.95$ \\
\hline Positive social interaction & $1.76(1.24-2.49), p=0.01^{*}$ & $1.50(0.74-3.07), p=0.26$ \\
\hline Male vs Female & $3.45(1.44-8.27), p=0.01^{*}$ & $0.31(0.11-0.90), p=0.03^{*}$ \\
\hline \multirow[t]{3}{*}{ Age } & 0 & 0 \\
\hline & $1.65(0.62-4.40), p=0.32$ & $10.30(0 . .34-3.15 .17), p=0.18$ \\
\hline & $0.61(0.23-1.63), p=0.32$ & $1.90(0.42-8.59), p=0.40$ \\
\hline \multirow[t]{3}{*}{ Education } & 0 & 0 \\
\hline & $1.19(0.48-2.93), p=0.71$ & $0.61(0.17-2.17), p=0.45$ \\
\hline & $1.12(0.45-2.79), p=0.82$ & $0.95(0.25-3.57), p=0.94$ \\
\hline \multicolumn{3}{|l|}{ Employment } \\
\hline FT/PT vs Retired/Not working & $0.73(0.28-1.92), p=0.73$ & $0.98(0.21-4.59), p=0.98$ \\
\hline Spouse vs Other & $1.51(0.69-3.28), p=0.30$ & $1.58(0.42-5.96), p=0.50$ \\
\hline \multicolumn{3}{|l|}{ Carer resides with PWD } \\
\hline Yes vs No & $2.30(0.90-5.60), p=0.09$ & $0.35(0.09-1.41), p=0.14$ \\
\hline \multirow[t]{3}{*}{ PWD level of dependence } & 0 & 0 \\
\hline & $1.39(0 . .46-4.19), p=0.56$ & $0.79(0.20-3.23) p=0.75$ \\
\hline & $1.35(0.50-3.61), p=0.55$ & $0.75(0.21-2.63), p=0.65$ \\
\hline
\end{tabular}

Table 2: Logistic regression model showing the odds ratio (OR) $95 \% \mathrm{Cl}$ and $p$ values with high resilient coping as the dependent variable. 


\section{Discussion}

This study has demonstrated that social support has a positive relationship with resilient coping. However, in response to our second hypothesis and in contrast to other carer studies $^{12,17}$ we found no single domain of social support predicts high resilient coping when other factors are controlled for. Critically, we have found that some carers feel they have no access to any social support, particularly in relation to tangible support to assist them in a crisis.

In this practical context, tangible support includes functions such as someone being available to 'help you if you were confined to bed,' and 'help with daily chores if you were sick $^{\prime 19}$. This lack of practical support is commonplace for carers generally ${ }^{25}$. It has implications for both the carer and the person with dementia, as both parties would be reliant on statutory services should the carer be unable to carry out practical activities of daily living due to illness or injury. A lack of practical support has also been associated with greater carer morbidity as individuals are not able to take a break or attend to their own health needs ${ }^{25}$, whereas the availability of tangible support has a positive influence on life satisfaction $^{26}$.

After tangible support, positive social interaction was the form of social support carers perceived to be least available. Carers of people with dementia are at greater risk of social isolation and declining social networks ${ }^{27,28}$. People with high resilient coping are more able to 'replace losses encountered in life'14 and this may enable them to develop new social support ties through dementia-related settings such as dementia cafes, support groups, and online forums. Commonality and shared experience in caring have been suggested as fostering resilience ${ }^{29}$ and these settings may provide such opportunities.

Affectionate support was perceived as the most available form of support for both high and low resilient carers. Resilient coping includes being able to adapt to new situations, and as the majority of participants in our study are spousal carers it maybe that high resilient carers 
find new ways to maintain affection in their marital relationship. Positive relationships between the carer and the person with dementia have been identified as important for resilience ${ }^{30}$. When defining resilience, carers rated 'spending time together in an enjoyable way' as a high priority ${ }^{31}$. Carer resilience is also associated with lower incidence of carer abusive behaviour towards the person with dementia ${ }^{32}$. Where a carer considers the person with dementia to be their main support, as in a mutual caring relationship, this is likely to change over time as the person with dementia becomes more dependent.

We found that low resilient carers reported significantly less availability of social support across all domains including emotional/informational support. In the UK, the Care Act ${ }^{33}$ places a duty on statutory services to provide advice and information to carers, so it is unexpected that some participants reported no access to this domain. For the low resilient carers who reported no access to emotional/informational support it may be argued that, although this support is available, it may be insufficient, not in a format accessible to the carer, not available at the right time, or does not address their specific concerns ${ }^{34,35}$.

We have also identified that that gender predicted high resilient coping, in this sample. This is in line with an earlier study of dementia carers ${ }^{36}$, which also found associations with resilience and age and ethnicity. The finding that women were more resilient than men in the current study contrasts with the normative data for the Brief Resilient Coping Scale which suggests that overall, men have higher resilient coping scores than women ${ }^{37}$ although the difference is small. However, the majority of dementia carers are women ${ }^{34}$ and this is reflected in the recruitment to this study, there were significantly more female participants so findings related to gender should be interpreted with caution.

None of the other socio-demographic characteristics we examined had a significant relationship with resilience. This adds to findings of studies in other populations. Sociodemographic factors including age, gender, marital status, employment and education did not influence resilience in people with chronic illness ${ }^{38}$. These findings suggest individual socio-demographic characteristics may have less influence on resilient coping than wider 
external factors. Likewise we found carer level of resilience was independent of the level of dependency of the person with dementia this supports the findings of Dias et $\mathrm{al}^{39}$ which highlighted a lack of significant relationship between carer resilience and clinical characteristics of the person with dementia.

There are some limitations in this study. The social support instrument used does not measure support asked for or received. It may be the case that low resilient carers did not feel able to ask for help so perceived that help was unavailable. The current study did not measure the number of people in each carer's social network so social support may have come from a single relationship or a wider field of friends and family. Therefore some carers who have reported they 'always' have access to social support may, in fact, have a rather fragile support system, reliant on the availability of one friend or family member. As this is a cross-sectional study we cannot confer cause and effect, it is not possible to say whether high resilient coping promotes greater access to social support or whether social support boosts carer resilient coping skills.

\section{Conclusion}

Our results show that when each domain of social support (emotional/informational support, tangible support, affection or positive social interaction) is considered individually, each of them have a positive relationship with high resilient coping. We have demonstrated that carers with high resilient coping skills perceive they have greater access to all forms of social support than those with low resilient coping. However, no one domain of social support predicts high resilient coping. Nurses and social care providers should enable carers to maintain existing, and develop new social support networks, to ensure they have access to the multi-dimensional social support required to support their resilience. 


\section{References}

1. $\quad$ Alzheimer's Research UK. Dementia in the Family. The impact on carers. Cambridge2015.

2. Seavey D. Family care and paid care: Separate worlds or common ground. Better Jobs Better Care Issue Brief. 2005;5.

3. Schulz R, Sherwood PR. Physical and mental health effects of family caregiving. Journal of Social Work Education. 2008;44(sup3):105-113.

4. Southwick SM, Bonanno GA, Masten AS, Panter-Brick C, Yehuda R. Resilience definitions, theory, and challenges: interdisciplinary perspectives. Eur J Psychotraumatol. 2014;5.

5. Rutter M. Resilience as a dynamic concept. Dev Psychopathol. 2012;24(2):335-344.

6. Hjemdal O, Friborg O, Stiles TC, Martinussen M, Rosenvinge JH. A New Scale for Adolescent Resilience: Grasping the Central Protective Resources Behind Healthy Development. Measurement \& Evaluation in Counseling \& Development. 2006;39(2):84-96.

7. Liu D, Fairweather-Schmidt A, Burns R, Roberts R. The Connor-Davidson Resilience Scale: Establishing Invariance Between Gender Across the Lifespan in a Large Community Based Study. Journal of Psychopathology \& Behavioral Assessment. 2015;37(2):340-348.

8. Gaugler JE, Kane RL, Newcomer R. Resilience and transitions from dementia caregiving. The Journals of Gerontology Series B: Psychological Sciences and Social Sciences. 2007;62(1):P38P44.

9. Kaizik C, Caga J, Camino J, et al. Factors Underpinning Caregiver Burden in Frontotemporal Dementia Differ in Spouses and their Children. Journal of Alzheimer's Disease. 2017;56(3):1109-1117.

10. Bruvik FK, Ulstein ID, Ranhoff AH, Engedal K. The effect of coping on the burden in family carers of persons with dementia. Aging \& mental health. 2013;17(8):973-978.

11. Conde-Sala JL, Garre-Olmo J, Turró-Garriga O, Vilalta-Franch J, López-Pousa S. Differential features of burden between spouse and adult-child caregivers of patients with Alzheimer's disease: An exploratory comparative design. Int J Nurs Stud. 2010;47(10):1262-1273.

12. Ruiz-Robledillo N, De Andrés-García S, Pérez-Blasco J, González-Bono E, Moya-Albiol L. Highly resilient coping entails better perceived health, high social support and low morning cortisol levels in parents of children with autism spectrum disorder. Research in Developmental Disabilities. 2014;35(3):686-695.

13. O'Rourke N, Kupferschmidt AL, Claxton A, Smith JZ, Chappell N, Beattie BL. Psychological resilience predicts depressive symptoms among spouses of persons with Alzheimer disease over time. Aging Ment Health. 2010;14(8):984-993.

14. Sinclair VG, Wallston KA. The development and psychometric evaluation of the Brief Resilient Coping Scale. Assessment. 2004;11(1):94-101.

15. Tomás JM, Sancho P, Melendez JC, Mayordomo T. Resilience and coping as predictors of general well-being in the elderly: A structural equation modeling approach. Aging \& Mental Health. 2012;16(3):317-326.

16. Pillemer SC, Holtzer R. The differential relationships of dimensions of perceived social support with cognitive function among older adults. Aging \& Mental Health. 2016;20(7):727735.

17. Roper L, Donnellan W, Hanratty B, Bennett K. Exploring dimensions of social support and resilience when providing care at the end of life: a qualitative study. Aging \& Mental Health. 2018:1-7.

18. Donnellan WJ, Bennett KM, Soulsby LK. What are the factors that facilitate or hinder resilience in older spousal dementia carers? A qualitative study. Aging \& Mental Health. 2015;19(10):932-939.

19. Sherbourne CD, Stewart AL. The MOS social support survey. Soc Sci Med. 1991;32(6):705714. 
20. RAND Health. Social Support Survey Instrument Scoring Instructions. 2018; https://www.rand.org/health/surveys tools/mos/social-support/scoring.html. Accessed 17.07.18, 2018.

21. Bucks RS, Ashworth DL, Wilcock GK, Siegfried K. Assessment of activities of daily living in dementia: development of the Bristol Activities of Daily Living Scale. Age Ageing. 1996;25(2):113-120.

22. Boyd PA, Wilks SE, Geiger JR. Activities of Daily Living Assessment among Nursing Home Residents with Advanced Dementia: Psychometric Reevaluation of the Bristol Activities of Daily Living Scale. Health \& Social Work. 2018;43(2):101-108.

23. Gignac GE. How2statsbook (Online Edition 1). Perth, Australia2019.

24. Wimo A, Reed CC, Dodel R, et al. The GERAS study: a prospective observational study of costs and resource use in community dwellers with Alzheimer's disease in three European countries-study design and baseline findings. Journal of Alzheimer's Disease.

2013;36(2):385-399.

25. Carers UK. Carers at breaking point. London: Carers UK. 2014;3.

26. Morlett-Paredes A, Perrin PB, Olivera SL, et al. With a little help from my friends: Social support and mental health in $\mathrm{SCl}$ caregivers from Neiva, Colombia. NeuroRehabilitation. 2014;35(4):841-849.

27. Clay OJ, Roth DL, Wadley VG, Haley WE. Changes in social support and their impact on psychosocial outcome over a 5-year period for African American and White dementia caregivers. International journal of geriatric psychiatry. 2008;23(8):857-862.

28. Han JW, Jeong H, Park JY, et al. Effects of social supports on burden in caregivers of people with dementia. Int Psychogeriatr. 2014;26(10):1639-1648.

29. Donnellan WJ, Bennett KM, Soulsby LK. Family close but friends closer: exploring social support and resilience in older spousal dementia carers. Aging \& Mental Health. 2016;21(11):1222-1228.

30. Deist M, Greeff AP. Living with a parent with dementia: A family resilience study. Dementia. 2017;16(1):126-141.

31. Joling KJ, Windle G, Dröes R-M, Huisman M, Hertogh CMPM, Woods RT. What are the essential features of resilience for informal caregivers of people living with dementia? A Delphi consensus examination. Aging \& Mental Health. 2017;21(5):509-517.

32. Serra L, Contador I, Fernández-Calvo B, et al. Resilience and social support as protective factors against abuse of patients with dementia: A study on family caregivers. International journal of geriatric psychiatry. 2018.

33. HM Government. Care Act. UK: http://www.legislation.gov.uk/ukpga/2014/23/contents/enacted 2014.

34. Georges J, Jansen S, Jackson J, Meyrieux A, Sadowska A, Selmes M. Alzheimer's disease in real life-the dementia carer's survey. International journal of geriatric psychiatry. 2008;23(5):546-551.

35. Robinson A, Elder J, Emden C, Lea E, Turner P, Vickers J. Information pathways into dementia care services: Family carers have their say. Dementia. 2009;8(1):17-37.

36. Dias R, Santos RL, Sousa MFBd, et al. Resilience of caregivers of people with dementia: a systematic review of biological and psychosocial determinants. Trends In Psychiatry And Psychotherapy. 2015;37(1):12-19.

37. Kocalevent R-D, Zenger M, Hinz A, Klapp B, Brähler E. Resilient coping in the general population: standardization of the brief resilient coping scale (BRCS). Health Qual Life Outcomes. 2017;15(1):251.

38. Böell JEW, da Silva DMGV, Hegadoren KM. Sociodemographic factors and health conditions associated with the resilience of people with chronic diseases: a cross sectional study. Revista Latino-Americana de Enfermagem. 2016;24:e2786. 
39. Dias R, Simoes-Neto JP, Santos RL, et al. Caregivers' resilience is independent from the clinical symptoms of dementia. Arquivos de neuro-psiquiatria. 2016;74(12):967-973. 